cochineal, silk insects, honey insects, medicinal insects, insects as protein resource, insects as natural enemies of pests, pollination insects, ornamental insects, environmental friendly insects, scientific value and application of insect cells, bio-reactor of insects, special abilities and bionic insects and so on. Each chapter introduces a large number of examples of specific types of insects and their biological and ecological characteristics, application values, research status at present, and the developmental trends, based on domestic and foreign research data or references. Both pictures and text are good enough. The book is a systematic monograph on the insect resources of China, especially the latest information on the resource entomological research.
This book will provide a valuable reference or teaching material for those engaged in teaching, technical or research work in entomology, agriculture, forestry, ecology, biology, environmental sciences and so on, or other persons who are interested in these fields.

\section{Li DEZHI ${ }^{1}$ AND QIN AILI ${ }^{2}$}

${ }^{1}$ Lab of Urbanization and Ecological Restoration of Shanghai; National Field Observation and Research Station in Tiantong Forest Ecosystem of Zhejiang; Department of Environmental Science, East China Normal University, 3663, Zhongshan Rd (N). Shanghai, China. 200062;

${ }^{2}$ Shanghai Vocational and Technical College of Agriculture and Forestry, 658 Zhongshan 2 Rd. Songjiang, Shanghai, China. 201600.

\title{
Mammals of India
}

By Vivek Menon. 2009. Princeton University Press, 41 William Street, Princeton, New Jersey. 208 pages, 35.00 USD Paper.

The Book of Indian Mammals by Prater [The Bombay Natural History Society] is, despite updates, a 60 -year-old book. The information is still valid, but the style is antiquated. The illustrations, by Paul Barrel, are excellent. However it is long past time for a new book. Vivek Menon's contribution is, therefore, most welcome.

The author provides full coverage [though not necessarily with an illustration] of just over 250 species of India's 400 or so mammal species. Some less frequently seen species get partial coverage, often as part of a comparison table.

There is an introduction to each family followed by a species account for most of the mammals you could see without going to unusual lengths [such as setting traps]. Each account covers a description, notes on behaviour, size and habitat. He gives the various local names too. The author also adds the places where you are most likely see the animal. Names are given in English and several Indian languages. The tiny range map shows its current distribution. A text box gives a quick reference to essential data [Scientific name, status, an estimate of the current population, diet, social unit, the time it is active and where you might find it]. All the species covered are illustrated by photographs, except the cetaceans. Key characteristics are highlighted by lines and appropriate text. There is a broader coverage than Prater's book, with more small mammals [mice, bats shrews etc.] included. The author does not cover sub-species.

The visitor to India will find this a very useful book for all the larger mammals. You will be able to identify similar species like Bonnet and Rhesus Macaque. You will have no difficulty identifying the common Sambar deer from the scarce Swamp deer. Small mammals, like mice and rats, will be more difficult, but that is not the fault of the book. For example, you should be able to separate and identify the striped squirrels. However I was not able to finalise the identity of a [Rhinolophus] horseshoe bat I photographed last year.

It is the larger, diurnal species that most people will see. The Gaur, for example, has a clear photo that shows its size, chocolate brown body and characteristic white "socks." The text tells you there are 20000 left in a declining population and it is most easily seen at $\mathrm{Mu}-$ dulmalai and Bandipur National Parks. The following entry for Yak notes there are less than 100 wild Yaks left in the Chang Chen Mo valley in Ladakh [10 000 in the world, compared to 14 million domestic Yaks].

Most people will focus on seeing a Tiger - a really magnificent beast. The national parks system is well organized to find a Tiger for visitors to see. The book recommends Rathambhor and Bandhavgarh parks, both excellent choices. Oddly, there are five times as many Leopards as Tigers, but the former are more difficult to see. Most of the other cats are confined to discrete portions of the Himalayas.

This is an excellent and much needed modern guide. It might not be detailed enough for a serious researcher, but it is great for the visitor. It is easy to use, with a lot of quality information packed into a book that only measures $21.5 \times 14 \times 1 \mathrm{~cm}$. The only "negative" comment I can make is that so many of the population figures are followed by "declining." In the conservation note, habitat loss and poaching are the dominant factors. It is sad to think that the beautiful, fascinating animals in this book could disappear from India's wonderful heritage. Buy the book and visit India soon.

ROY JOHN

2193 Emard Crescent, Ottawa, Ontario K1J 6K5 